\title{
An Investigation of the Effect of Initial Income Distribution on Household Consumption in
}

\section{China}

Chuanwen Song

School of Public Administration, Dongbei University of Finance and Economics,

Heishijiao, Shahekou, Dalian, China

Rong ZHANG

Faculty of Design, Nishinippon Institute of Technology

Kitakyushu, Fukuoka, Japan

\section{About the author}

Chuanwen Song is currently a registered student at the master course of School of Public Administration, Dongbei University of Finance and Economics in China. Partially due to this working experience at a bank, he is interested in doing research on economic and social problems in China from the perspectives of economic sociology and sustainable development. Chuanwen Song can be contacted at songchuanwen@163.com.

Dr. Rong Zhang is an Associate Professor at Nishinippon Institute of Technology, Japan. She has been teaching English and Chinese in Japan for nearly 20 years. Her research interests include foreign language teaching, educational management and comparative study on social issues. 


\section{Abstract}

This paper examines the effect of the distribution of national income on household consumption in China based on data from thirty provinces between the years 1993 to 2011. The results show that labor income has a greater impact on household consumption than profit income at the national level, but inter-provincial heterogeneity is also indicated due to regional differences. Profit income plays a decisive role in household consumption in the eastern area, while labor income functions are more significant in the central region. Thus, it is suggested that improvements in income should be based on a fairness policy in order to protect employees' working rights and opportunities while also considering regional differences.

Keywords: labor income, profit income, household consumption, resident revenue, regional differences

\section{Introduction}

Since China opened its doors to the world in 1978, it has experienced rapid economic growth, but at the same time, unbalanced distribution of the national income. This has become an issue, particularly in the 21st century, and there is concern of impending social problems. China's labor income share (labors' remuneration to GDP) has continued to decline over the past two decades, and according to the China Statistical Yearbook for the calendar years 1994-2012, China's labor income share fell from 49.49\% in 1993 to $44.94 \%$ in 2011, a drop of 4.55 percentage points. At the same times, however, there has been a small increase in profit income share (operating surplus as a percentage of GDP), which rose from $24.78 \%$ in 1993 to $26.54 \%$ in 2011 , a positive change of 1.76 percentage points.

China's national income distribution indicates a more serious imbalance when compared with the situation in other developed countries. In 2005, the labor income share in China was only $41.4 \%$, while the figure was over $50 \%$ in most of the developed countries, $60.3 \%$ in America, $63.6 \%$ in Europe and $58.8 \%$ in Japan. China's labor income share fell by 10.3 percent from 1995 to 2005, which is much higher than the negative 1.2 percent change in the US, the negative 1.8 percent change in Europe and the negative 4.3 percent change in Japan during the same period. With the unbalanced distribution of the national income and the fall in labor income share, China's resident consumption rate (consumption as a share of GDP) fell from $44.43 \%$ in 1993 to $35.41 \%$ in 2011. This is far below the 71.57 percent in the US, the 60.40 percent change in Japan and the 57.21 percent change in India. Thus, the share of disposable income going to residents in China has continued to fall since its peak in 1996 (Bai and Qian, 2009; Xue and Wei, 2003).

Household consumption is a major indicator of fiscal policy and the propagation of business cycle. Income distribution is closely related to the issue of social equality and Alestina and Angeletos (2003) believe that in a society where fairness and justice works well, individual efforts are highly evaluated and income distribution is equitable. Equality in consumption represents equality in social life (Liu, 2010). The interaction of income inequality and choice of redistributive policies affects the quality of life of residents and governments should protect fairness and justice in residents' income and consumption in order to realize sustainability in economic 
development (Wu, 2011). In the case of China, not all residents have benefited from the economic growth and the relationship between the income distribution imbalance and residential consumption must be further examined.

This article investigates China's national income distribution in different areas and the relationship among labor income share, profit income share and residents' consumption. It aims to shed more light on how to solve social problems related to fairness, justice and equality.

\section{Literature Review}

It is a widely accepted concept that there is a close relationship between the initial distribution of national income and the proportion of household income (Liu and Cai, 2010). It has been pointed out that low wages are the most significant factor to explain stagnation in consumption growth. Huang and Wei (2010) show that the Chinese consumption is significantly affected by the household wages. Therefore, the key to the expansion of the domestic consumption is to raise the proportion of workers' compensation in the initial distribution within the range of national disposable income. Chu and Yan (2011) present empirical results based on the 1993-2009 provincial panel data in China and draw that conclusion that the domestic consumption tends to rely heavily on the share of laborers' revenue. They further emphasize that raising workers' wages is an effective tool to enhance the purchasing ability of consumers to stimulate the demand for products and services in the long run. Zheng and Huang (2012) use the data from Jiangxi province to show that increasing household revenue succeeded in helping to promote consumption at the local area and has proved to play a more important role than the profit income.

A number of studies have focused on the relationship between income distribution and household consumption in China. Details can be found in the works of Zhu, Fan and Yan (2002), Feng (2004), Li and Yin (2007), Fang (2009) examined the relationship from the perspective of overall national disposable income and its influence of the income change on household consumption. The results support the fact that the total amount of income available to residents for consumption is closely related to the initial distribution pattern. Wang (2007) finds that the ratio of labor income share to national disposable income is at excessively low levels initially, which is the crucial reason responsible for the relatively slow development in domestic consumption. Wei Zhong (2010) points out that the rapid decrease in the proportion of the remuneration of national laborers in the initial distribution has led to low disposable household income and low consumption growth rates in China. Aziz and Cui (2007) also support the conclusion that the declining share of household income in national income is responsible for the low share of consumption in total expenditure. Consequently, household income and consumption power can be strengthened through the improvement of the initial distribution pattern of national income.

Furthermore, many researchers point out that inequality in household income through initial distribution is the major factor causing inequality in consumption. Gan (2013), for example, states that high income inequality is a major factor in creating the depressing level of consumption. Borooah and Sharpe (1986) investigate inequality in household income and consumption expenditure in detail by using the British 1963- 
1982 family annual survey data. The data are divided into five categories and the estimated consumption show significant difference among the various income groups. Cutler and Katz (1992) notice the change in the income and consumption distribution in US in the 1980s and suggest that the changes have brought about inequality in household income and consumption. Moreover, they point out that the change in the distribution of the labor market wages is the underlying factor for the change of family income and consumption inequality. Aguiar and Bils (2011), using data on the US, also highlight the importance of income inequality in the growth of consumption inequality using various methods of measurements. The results of a study on China by Chen and Zhou (2010) find that about two-thirds of total income inequality can be attributed to labor income inequality, which is a relatively consistent phenomenon in Chinese society.

Although the above literature review gives a description of the impact of disposable household income on consumption expenditure from an overall perspective, most of them are qualitative studies, which do not provide sufficient explanation for the detailed structure of household income. Because the factors consisting of household income are not clarified, the conclusions are not as comprehensive and feasible as expected. In addition, recent research on the topic of income distribution and residents' consumption tends to ignore inter-provincial heterogeneity. While empirical studies are conducted by using provincial panel data of China, the effect of differences in regional variables are generally ignored. In fact, due to geographical and historical backgrounds, different features can be seen at the various development stages in the respective areas. Provinces rely on their own sources for economic development, and the different development patterns may have different influences on the income and consumption situation. The current national income distribution policy is based on a general regulation to balance disposable income and consumption, without taking into account regional and provincial "heterogeneity". They may bias the efforts to find a solution to address income inequality. Ramstetter, Erbiao and Sakamoto (2008), for example, remark that "national accounts data and household survey data from the National Bureau of Statistics both indicate a tendency for the incomes to rise faster in the East of the country than in the Center and the West", and "intra-regional distribution tended to be more equal in the Center and the West than in the East". This clearly indicates provincial heterogeneity in national and household incomes and the distribution pattern in different areas. Many studies fail to offer comprehensive and persuasive perspectives on this issue due to the failure to address regional heterogeneity.

The purpose of this paper is to address the issue of provincial heterogeneity in an attempt to balance national income and household income through primary distribution so that domestic consumption expenditure can be increased. A panel data model is used as the underlying basis for analysis in this study and provincial heterogeneity is taken into serious consideration. Suggestions are made on how to reform the Chinese income distribution system and how to expand the domestic demand market is discussed.

\section{Model Specification and Methodology}

Based on the consumption model of Marglin and Bhaduri (1990), the consumption model employed in this study is specified below. The feature of their model lies in its strong expressiveness of "the impact of 
functional income distribution on the growth in demand" (Hartwig, 2014). One drawback, however, is its lack of flexibility (John, 2009). Therefore, we establish a new model for the analysis of the consumption. In our proposed BM model, gross national income $(Y)$ consists of wage income $(W)$ and profit income $(R)$. Thus, residents' consumption $(C S)$ can be expressed as following:

$$
C S=C S(W, R)
$$

According to Equation (1), we can build our panel model for the initial distribution of national income by adding more variables into the model to strengthen its dynamics and accommodation ability:

$$
C S=\alpha_{0}+\alpha_{1} W_{i t}+\alpha_{2} R_{i t}+\varepsilon_{t}
$$

In Equation (2), $\alpha_{0}$ is a constant, $\alpha_{1}$ and $\alpha_{2}$ refer to the impact level of the wage income and the profit income on residential consumption, respectively, and $\varepsilon_{t}$ is the random error. The subscripts $i$ and $t$ represent provinces and time, respectively.

Selected panel data of 30 provinces in China are used for the empirical tests in this paper. Laborers' remuneration is used as the measurement of wage income $(W)$, and operating surplus is used for the measurement of profit income $(R)$. The data set for the 30 provinces was selected because the first statistical data of the Chinese laborers' remuneration and the operating surplus at the provincial level were collected in 1993. Although there are 31 administrative provinces throughout the nation, the data of Tibet was missing for a number of elements so this province was dropped.

In order to eliminate the influence of price factors, the index of Gross Domestic Product (GDP) for 1978 in each respective province is used as the deflator $(1978=100)$ for laborers' remuneration and operating surplus. The provincial consumer price index in 1978 is the index for all the consumer data (1978=100).

All of the raw data related to residents' consumption, labor remuneration, operating surplus and GDP at the provincial level from 1993 to 2004 are derived from Data of Gross Domestic Product of China published by China Statistical Publishing House. The data for the period 2005-2011 are from the China Statistical Yearbook. The provincial index of consumer price of 1993-2011 is available from the CEInet statistics database.

The natural logarithm transformation is conducted on Equation (2). According to Que and Ma (2010), the natural logarithm transformation does not change the cointegration of all the data items and the parameters. In addition, it can better describe the tendency of the calculated figures and reduce heteroskedasticity in time series data. The natural logarithm transformation is conducted on the deflated data. Thus, equation (3) is as follows:

$$
\operatorname{LnCS}=\alpha_{0}+\alpha_{1} L n W_{i t}+\alpha_{2} L n R_{i t}+\varepsilon_{t}
$$

Equation (3) shows the independent variable's contribution to Chinese household consumption and indicates the influence of the initial distribution of national income on Chinese residents' consumer expendi- 
ture. Due to According to the China economic information network (http://www.cei.gov.cn/), statistical database is divided into eastern, central and western regions. The eastern region includes Beijing, Tianjin, Hebei, Liaoning, Shanghai, Jiangsu, Zhejiang, Fujian, Shandong, Guangdong, Guangxi and Hainan and other 12 provinces; The central region includes Shanxi, Inner Mongolia, Jilin, Heilongjiang, Anhui, Jiangxi, Henan, Hubei and Hunan and other 9 provinces; The western region includes Chongqing, Sichuan, Guizhou, Yunnan, Shanxi, Gansu, Qinghai, Ningxia and Xinjiang and other 9 provinces. The result is recorded as model I. The data for the 30 provinces are then divided into three regions: Eastern, Central and Western. The data for the respective regions are evaluated using Equation (3) in order to capture the features of the regional income distribution structure and its impact on residents' consumption. The results for these three regions are recorded as model II, III and IV, respectively.

\section{The empirical analysis and results}

\section{Estimates of the overall results}

In order to avoid spurious regression, the commonly-accepted unit root test is adopted in this study to examine the existence of non-stationary time series. If unit roots are not rejected, then the difference operator should be applied to the series to eliminate the unit roots. Time series with unit roots generally show apparent memorability and volatility, therefore, the testing of cointegration and serial volatility persistence is the basic for a unit root process. Co-integration determines whether a non-stationary linearity has a stable equilibrium, which is the prerequisite for building an equation to further investigate the issue.

Panel unit root test

The commonly accepted unit root test for cointegration analysis includes LLC - test for the panel data with homogeneity, IPS - test for panel data with heterogeneity, the well-known Fischer - ADF test and the Fischer - PP test. In order to enhance the consistency of the results, all of these four methods are employed in this

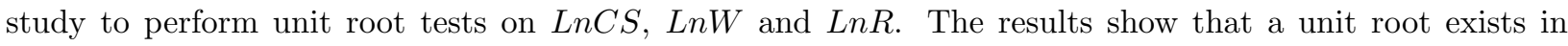
the original sequence of all the variables at the $1 \%$ significant level, and their first order difference is stable. Therefore, cointegration analysis is feasible and meaningful.

\section{Panel cointegration test}

The results from both the Kao-test and Fischer-test show that a cointegration relationship exists among $L n C S, L n W$ and $L n R$ at the $1 \%$ significant level in model I.

Panel estimation results and analysis

The result of the F-test suggests that a variable intercept function should be employed for Model I to enable sufficient analysis of the different effects of the independent variables. Furthermore, the results of the Hausman - test implies that model I should be set as the fixed effect variable intercept model. The estimated results are shown as in table 1. 
The unit root test results based on the LLC-test, the IPS-test, the Fisher - ADF and the Fisher - PP for Model I show that the panel residual is stable at the $1 \%$ significant level. This suggests that the estimate results in this study are sound and consistent.

Table 1 indicates that both $L n W$ and $L n R$ have a significant impact on Chinese residents' consumption. However, wage income has a greater influence on the residents' consumption. Provided that all other conditions are invariant, Chinese residents' consumption will increase by $1.1986 \%$ for every $1 \%$ increase in the wage income, but only by $0.8869 \%$ for every $1 \%$ increase in the profit income.

Table 1 Estimation Results of Model I

\begin{tabular}{cc}
\hline Explanatory variables & Values \\
\hline LnW & $1.1986^{* * *}[21.54]$ \\
LnR & $0.8869^{* * *}[33.53]$ \\
$\mathrm{R} 2$ & 0.9498 \\
Adj R & 0.9469 \\
F-statistic & 328.3503 \\
Prob (F-statistic) & 0.0000 \\
Number of observations & 570 \\
\hline
\end{tabular}

Note: The values in brackets are $\mathrm{t}$ statistics; ${ }^{* * *}$ indicates that the estimated parameters are significantly different at the $1 \%$ significant level.

\section{Estimated results and analysis for local regions}

Panel unit root test

This paper also uses LLC, IPS, Fisher-ADF and Fisher-PP test methods to inspect the unit root of the variables in model II, Model III and Model IV. The results show that a unit root exists in the original sequence of the variables in all three models at the $1 \%$ significant level and their first order difference is stable.

\section{Panel cointegration test}

The results from both the Kao-test and Fischer-test show that there is a consistent and stable cointegration relationship among $\operatorname{LnCS}, \operatorname{Ln} W$ and $\operatorname{LnR}$ at the $1 \%$ significant level in Model II, Model III and Model IV.

\section{Panel estimation results and analysis}

An $\mathrm{F}$ test and Hausman test are conducted for the data in the three models. The results show that the variable intercept fixed effect function should be employed for Model II, Model III and Model IV. The estimation results are indicated in table 2 .

Based on the results of unit root tests using the LLC, IPS, Fisher-ADF and the Fisher-PP method, all panel residuals in all three models show stable tendency at the $1 \%$ significant level. Thus, it is concluded that estimate results for all three models are reasonable and sensible. 
According to table 2, both wage income and profit income have a significant positive impact on regional consumption in all three areas (eastern region, central region and western region) at the $1 \%$ significant level. Specifically, in the eastern region, consumer expenditure increases by $1.1155 \%$ for every $1 \%$ increase in the wage income and $1.2856 \%$ for every $1 \%$ increase in profit income. In the central region, every $1 \%$ increase in the wage income and the profit income can bring about a growth of consumer spending growth of $1.1368 \%$ and $0.8403 \%$ respectively. In terms of the western region, each $1 \%$ increase in wage income and profit income promotes consumer spending by $1.0152 \%$ and $0.5428 \%$ respectively. It is also implied from table 2 that in the eastern region, the impact of profit income on promoting consumers' expenditure is greater than wage income. However, in the central and western regions, wage income exerts a stronger influence on residents' consumption. Comparing elasticity of consumption in the three regions, wage and profit income elasticities of consumption measured by wage and profit income, profit income is the primary determinant of consumption in the eastern region, while wage income has more crucial effect on consumption in the central region. In the western region, the impacts of both wage and profit income on residential consumption are the weakest.

Table 2 Estimation Results of Model I

\begin{tabular}{cccc}
\hline Models Explanatory variables & Model II & Model III & Model IV \\
\hline LnW & $1.1155^{* * *}[41.39]$ & $1.1368^{* * *}[23.28]$ & $1.0152^{* * *}[22.16]$ \\
LnR & $1.2856^{* * *}[48.30]$ & $0.8403^{* * *}[50.03]$ & $0.5428^{* * *}[15.93]$ \\
R2 & 0.9970 & 0.9889 & 0.9915 \\
Adj R & 0.9968 & 0.9882 & 0.9909 \\
F-statistic & 5414.7380 & 1426.1440 & 1860.1120 \\
Prob (F-statistic) & 0.0000 & 0.0000 & 0.0000 \\
Number of observations & 228 & 171 & 171 \\
\hline
\end{tabular}

Note: The values in brackets are t statistics; ${ }^{* * *}$ indicates that the estimated parameters are significantly different at the $1 \%$ significant level.

\section{Discussion on social equality}

The estimation results based on the panel data indicates that even with the consideration of provincial heterogeneity, labor income affects the purchasing behavior of the consumers more significantly than the profit income in all regions except the eastern area. Improvement of labor income is the most crucial element in the expansion of domestic demand and the promotion of residential consumption. But, as mentioned above, China's current national income distribution reveals a constant reduction in the proportion of labor income in GDP. The rise in the proportion of profit income has not only restricted residential consumption from growing, but has also aggravated the income inequality at the national level. The following three reasons help to explain the undesirable situation: 


\section{The Inequality in Employment}

At the current stage, China has not yet created a fair and effective employment system. Discrimination based on identity, gender, religious belief and birthplace still exists in many enterprises. The salary for migrant workers from undeveloped areas is relatively low and there is no sound salary growth and supervision mechanism to protect their rights. Since these workers are usually employed as temporary or contract workers, it is difficult for them to receive similar social benefits as local workers. In developed areas like in the east, the situation is better than other regions. Nevertheless, reducing social inequality through the distribution device of national income is still a very challenging issue.

\section{Inequality in Education}

Unequal educational resource allocation is one of the most challenging tasks that China has to face. Due to the disparity in education, populations in the rural areas, especially in the central and western regions, tend to experience much less employment training opportunities. This results in relatively low work skills for the surplus migrant laborers who transfer to the cities. In most cases, these workers have to confront discrimination in employment and are only able to get access to lowly paid positions which don't require

special techniques or skills. The regional imbalance in educational resources has contributed directly to the unbalanced economic development and the huge gap between the top and the bottom levels of society. The limited educational background has also prevented migrant workers from undeveloped regions from gaining the same opportunities in the workplace as the local labor. This negatively impacts remuneration and contributes to economic inequality.

\section{The Relatively Heavy Production Taxes}

Since China started its economic reform policy in 1978, the growth rate of net taxes on products has shown an overall downward trend. National production tax revenue, for example, dropped by $24.7 \%$ from 1978 to 2010. However, production tax revenue still accounted for $64.7 \%$ of national tax revenues in 2010. Of this, the proportion of the total amount of goods and service tax has been constant at a level of $60.8 \%$. Recently, however, production tax revenue has increased rapidly. Figure 1 shows changes in the net product tax, labor income and GDP during 1994-2011. The nominal growth rates of all three items have been maintained at a level of more than five percent. But production tax revenue shows a higher growth rate than GDP and labor income, and the growth rate of labor income is the lowest rate of the three. The sudden drop in the net taxes on products of 2009 was caused by the economic recession worldwide that year.

\section{Conclusion}

This paper employs panel data from 30 provinces in China and conducts an empirical examination on the impacts of the initial distribution of national income on household consumption during 1993-2011 at both 


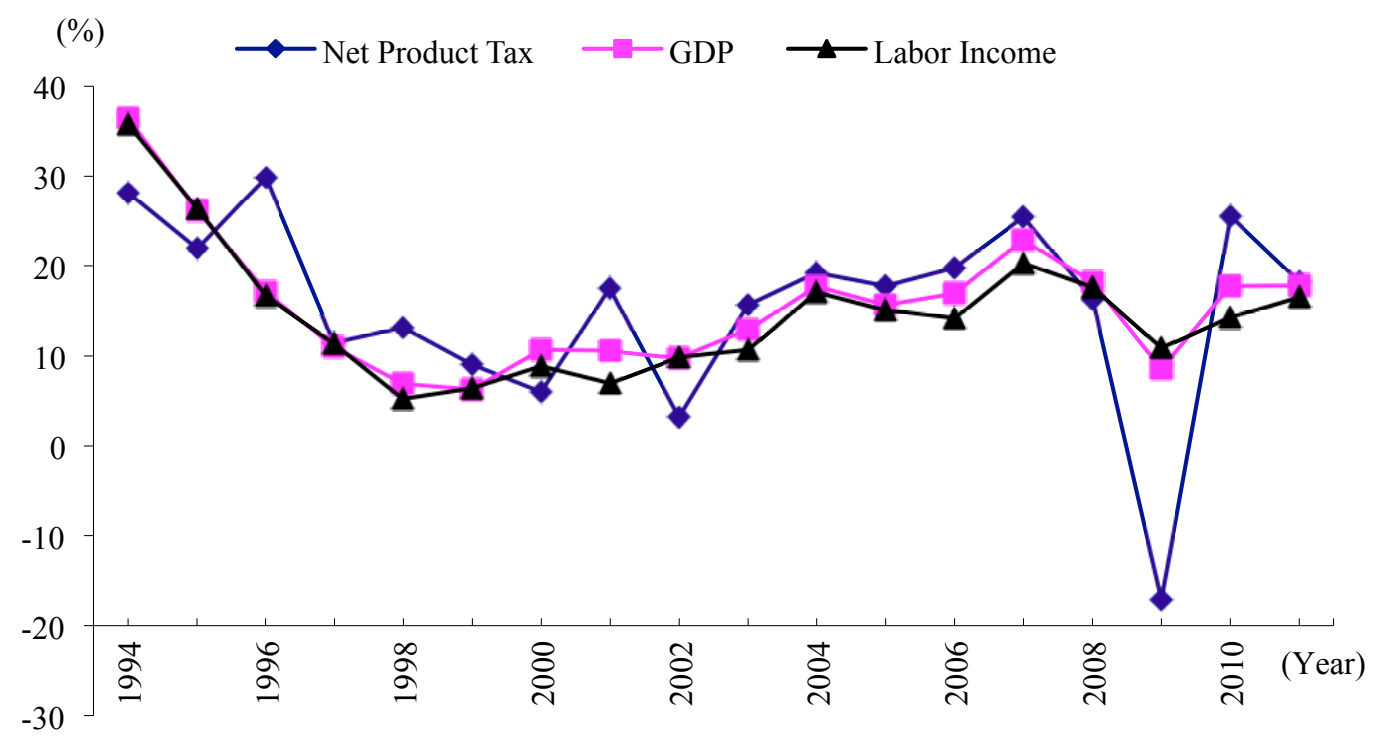

Fig. 1 Nominal Growth Rate of China's production tax, labor income and GDP (Data sources: China Statistical Yearbook during 1995-2012)

national and sub-regional levels. The results show that labor income has a greater impact on household consumption than profit income at the national level. But when considering inter-provincial heterogeneity, the effects of labor and profit income on household consumption differ at the sub-regional level. Profit income plays the most important role in promoting household consumption in the eastern area, but the labor income is most important in the central region. Neither labor nor profit income has crucial effect on household consumption in the western region.

The conclusion offers important insight on the reform of the income distribution system in China. From the long run perspective, the increase in China's consumption depends largely on the increased share of the laborers' wages. In order to expand the domestic demand, the government should take effective measures to support fairness and justice in the initial distribution of national income in order to delete uncertainty in consumption (Wang and Cai, 2007). This is of special importance under the current situation in which the share of laborers' remuneration has been decreasing in China. The purpose of such policies is not only to narrow the gap in income between the top and the bottom levels, but also to increase the real purchasing power of the residents at the national level. China's current institutional framework is an impediment to the transformation of a more energetic domestic demand market. It "weakens the incentives of households to consume" (Wang, 2014). Reforms on the national income distribution are needed to realize consumption driven growth. Governments should improve the income level for all the residents and make adjustment on income distribution through a more effective structural framework (Qian, Zhao and Zhong, 2013).

Certainly, the key to eliminating social inequality lies in the efforts to get rid of discrimination in both education and employment. Equal rights for both education and employment should be protected by law 
through balanced development of the urban and the rural areas. China needs to develop its national competitiveness to realize real sustainable development.

\section{References}

Aguiar, M. and Bils M., 2011. "Has Consumption Inequality Mirrored Income Inequality?", NBER Working Paper No. 16807. Accessed on April 23, 2014 at http://www.nber.org/papers/w16807.

Alestina, A. and Angeletos, G., 2003. "Fairness and Redistribution: US versus Europe", Harvard Institute Research Working Paper No. 1983; MIT Department of Economics Working Paper No. 02-37. Accessed on April 21, 2014 at http://papers.ssrn.com/sol3/papers.cfm?abstract_id=346545.

Aziz, J. and Cui, L., 2007. "Explaining China's Low Consumption: The Neglected Role of Household Income". International Monetary Fund Working Paper. Accessed on April 22, 2014 at https://www.imf.org/external/pubs/ft/wp/2007/wp07181.pdf.

Bai, C. and Qian, Z., 2009. "Who Has Eroded Residents' Incomes? An Analysis of China's National Income Distribution Patterns", Social Sciences in China, Issue 2009-05, pp. 99-115.

Borooah,V. and Sharpe,D., 1986. "Aggregate Consumption and the Distribution of Income in the United Kingdom: An Economic Analysis". The Economic Journal, Vol. 96, No. 382, pp. 449-466.

Cai, H., Chen, Y. and Zhou, L., 2010. "Income and Consumption Inequality in Urban China: 1992-2003", Economic Development and Cultural Change, Vol. 58, Issue 3, pp. 385-413.

Chu, D. and Yan, W., 2011. "Chuci Fenpei dui Jumin Xiaofei de Yingxiang Jili ji Shizheng Yanjiu", Public Finance Research, Issue 2011-03, pp. 57-61.

Cutler, D. and Katz, L, 1992. "Rising Inequality? Changes in the Distribution of Income and Consumption in the 1980s", American Economic Review, Vol. 82, No.2, pp. 546-551.

Dreger, C., Wang, T. and Zhang, Y., 2014. "Understanding Chinese Consumption: The Impact of Hukou", BOFIT Discussion Paper No. 7/2014. Available on April 21, 2014. http://papers.ssrn.com/sol3/ papers. cfm?abstract_id=2410216.

Fang, F., 2009. "A study of inadequate consumer demand among Chinese residents - based on data for urban and rural areas in different provinces", Social Sciences in China, Vol. 30, Issue 4, pp. 21-49.

Feng, D., 2004. "On Income Policies about Increasing Households' Consumption Expenditure", Journal of Zhengzhou Textile Institute, Issue 2004-03, pp. 66-69.

Gan, L., 2013. "Income Inequality and Consumption in China". Global Economic Symposium. Available on April 22, 2014 at http://www.global-economic-symposium.org/knowledgebase/social-norms-andmoral-principles-to-reduce-poverty-and-improve-equity/background-paper.

Hartwig, J., 2014. "Testing the Bhaduri-Marglin Model with OECD Panel Data", KOF Working Papers No. 349. Available on April 24, 2014 at http://papers.ssrn.com/sol3/papers.cfm?abstract_id=2387377. Huang, Q. and Wei, X., 2010. "Effects of Decreasing Share of Labor Incomes in China", Finance \& Trade Economics, issue 2010-04, pp. 121-127.

John, K., 2009. "A System Dynamics Approach to the Bhaduri - Marglin Model", Conference Proceedings 
of the 27th International Conference of the System Dynamics Society held in July, 2009 in New Mexico, USA.

Li, Y. and Yin, J., 2007. "Anatomy of High Saving Rate of China: Analysis Based upon Flow of Funds Account of China from 1992 to 2003", Economic Research Journal, Issue 2007-06, pp. 14-26.

Liu, S., 2010. "Xiaofei Gongping, Qidian Gongping yu Shehui Gongping" (Consumption Fairness, Startingpoint Fairness and Social Equality), Taxation Research, Vol. 2010-03, pp. 14-17.

Liu, W. and Cai, Z., 2010. "Guonei Zongxuqiu Jiegou Maodun yu Guomin Shouru Fenpei Shiheng”, Economics Perspectives, Vol. 2010-07, pp. 19-27. Beijing, China: Institute of Economics, Chinese Academy of Social Sciences.

Marglin, S. and Bhaduri, A., 1990. "Profit Squeeze and Keynesian Theory", in Marglin, S. and Schor, J. (eds.), The Golden Age of Capitalism: Reinterpreting the Postwar Experience, pp. 153-186. Oxford: Clarendon Press.

Qian, L., Zhao, Y. and Zhong, S., 2012. "The Empirical Analysis of the Impacts of Income Distribution Gap on Consumption Demand: Based on the Statistic Data of Chinese Urban Residents in 2000-2010", Chinese Journal of Population Resources and Environment, Vol. 10, Issue 4, pp. 116-120. Taylor and Francis Online.

Que, C. and Ma, B., 2010. "Jiyu VAR Moxing de Zhongguo Jumin Xiaofei yu Jingji Zengzhang de Guanxi" (Relationship between household consumption and economic growth in China based on VAR model), Journal of Dalian Maritime University, Vol. 4, pp. 68-73.

Ramstetter, E., Erbiao, D. and Sakamoto, H., 2008. "Recent Trends in China's Distribution of Income and Consumption: A Review of the Evidence", Working Paper Series Vol. 2006-23, The International Centre for the Study of East Asian Development, Kitakyushu. Accessed on April 22, 2014 at http://www. icsead.or.jp/user03/833_184_20110622112913.pdf.

Wang, T., 2007. "Gaige Shouru Fenpei Tixi Jiejue Touzi Xiaofei Shitiao", China Securities Daily, Available on April 21, 2014 at http://news .xinhuanet.com/fortune/2007-10/29/content_6967850.htm.

Wang, T. and Cai, Y., 2007. "Policy Recommendation for Balancing Income Distribution", The China Economist, Vol. 2007-04, pp. 13-21.

Wei, Z., 2010. "Zhongguo Dangqian de Shouru Fenpei Zhuangkuang ji Duice Fenxi", Economics Perspectives, Issue 2010-08, pp. 55-61. Beijing, China: Institute of Economics, Chinese Academy of Social Sciences.

Wu, B., 2011. Consumption and Management: New Discovery and Applications. Chandos Publishing.

Xue, J. and Wei, Z., 2003. "Unemployment, Poverty and Income Disparity in Urban China",Journal of the East Asian Economic Association, Vol. 17, Issue 4, pp. 383-405.

Zheng, Y. and Huang, S., 2012. "Laodongzhe Baochou Shouru Fenpei yu Jumin Xiaofei ji yu Jiangxi-Sheng de Shizheng Yanjiu", Sub National Fiscal Research, Issue 2012-08, pp. 16-20.

Zhu, G., Fan, J. and Yan. Y., 2002. "On China's Consumption Sag and Income Distribution", Economic Research Journal, Year 2002, Issue 5, pp. 72-80. 